\title{
Structural Characterization and Antibacterial Activity of Antibiotic Streptomycin Immobilized on Zeolite Synthesized from Natural Kaolinite
}

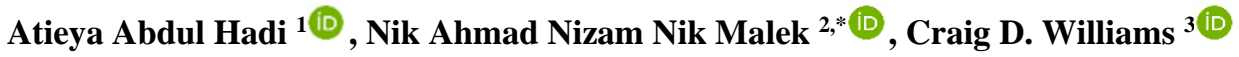 \\ 1 Department of Biosciences, Faculty of Science, Universiti Teknologi Malaysia (UTM), 81310 UTM Johor, Malaysia; \\ atieya@graduate.utm.my (A.A.H.); \\ 2 Centre for Sustainable Nanomaterials (CSNano), Ibnu Sina Institute for Scientific and Industrial Research (ISI-ISIR), \\ Universiti Teknologi Malaysia (UTM), 81310 UTM Johor, Malaysia; niknizam @ utm.my (N.A.N.N.M.); \\ 3 Faculty of Science and Engineering, University of Wolverhampton, Wulfruna Street, Wolverhampton, WV1 1LY, UK; \\ c.williams@wlv.ac.uk (C.D.W.); \\ * Correspondence: niknizam@utm.my;
}

Scopus Author ID 35995651900

Received: 6.01.2021; Revised: 5.02.2021; Accepted: 8.02.2021; Published: 13.02.2021

\begin{abstract}
This study evaluated the efficacy of antibacterial activities for a zeolite A (ZEO) sample loaded with streptomycin (STR). The ZEO was synthesized from kaolinite (KAO) via the alkaline hydrothermal process and verified with various techniques, such as X-ray Diffraction, FourierTransform Infrared spectroscopy, Field Emission Scanning Electron Microscopy with Energy Dispersive X-ray, Transmission Electron Microscopy, and dispersion behavior to confirm the production of ZEO with high purity and reproducibility. The cubic framework of ZEO was maintained after the immobilization of STR, indicating STR molecules' adsorption on the ZEO surface. The STRloaded ZEO (ZS) samples were prepared in three STR concentrations (50, 100, and $200 \mathrm{mg} / \mathrm{L}$ ). The samples' antibacterial activity was determined using the disc diffusion technique and minimum inhibition concentration against Gram-negative bacteria (Escherichia coli ATCC 11229) and Grampositive bacteria (Staphylococcus aureus ATCC 6538). Both bacteria were susceptible to ZS, which showed an antibacterial effect directly proportional to the STR concentration. Thus, the synthesized ZEO synthesized from natural KAO had a good prospect as a carrier system for STR for generating a broad spectrum of antibacterial activity.
\end{abstract}

Keywords: antibacterial agent; hydrothermal; kaolinite; streptomycin; zeolite.

(C) 2021 by the authors. This article is an open-access article distributed under the terms and conditions of the Creative Commons Attribution (CC BY) license (https://creativecommons.org/licenses/by/4.0/).

\section{Introduction}

Multidrug resistance in pathogenic bacteria has become a significant threat to public health and food security. In 2014, the World Health Organization (WHO) declared that antimicrobial resistance (AMR) is one of the top 10 global public health threats to humanity. This threat becomes more severe when pathogens rapidly adapt against antimicrobials largely because new antimicrobial agents' development was very slow[1, 2]. In this respect, the antibiotic is an excellent antibacterial agent used to facilitate the immune system in fighting and stopping bacterial infections. However, long-term exposure to antibiotics and improper usage of antibiotics would rapidly lead to the development of antibiotic-resistant bacteria [3]. Antibiotic resistance happened when the bacteria managed to overcome the functionalities of bacteria. Thus, there is a growing need to improve the efficacy of existing antibacterial agents 
or even develop new antibacterial to battle against the fast-evolving antibiotic-resistance bacteria [4].

Various techniques are being used to develop new alternative effective antibacterial agents. Historically, clay has been used for medicinal purposes over the millennium. By dissolving clays in appropriate solvents, the oxidized metals (e.g., $\mathrm{Fe}, \mathrm{Al}, \mathrm{Ca}$, etc.) in clays would be released to suppress the pathogenic bacteria. In general, the mineral-rich clays generate a low $\mathrm{pH}(<4.6)$ condition through mineral oxidation and hydrolysis, and the produced reactive oxygen species (ROS) would destroy bacteria via pyrite oxidation. The low $\mathrm{pH}$ and oxidative environment would produce abundant cations of $\mathrm{Fe}^{2+}$ and $\mathrm{Al}^{3+}$ that synergistically attack pathogenic bacteria by damaging their cellular components. These cations would agglomerate on cell envelopes, impairing membranes through protein misfolding and oxidation [5]. Among these clays, the mineral-rich zeolite has been demonstrated to suppress the growth of various bacteria. Simultaneously, its tetrahedral atomic framework allows the sitting of an antibacterial compound for forming cationic species [6]. The immobilization of antibacterial compounds such as $\mathrm{Fe}^{2+}, \mathrm{Al}^{3+}$ in the zeolite framework has been demonstrated to have excellent antimicrobial performances on Gram-positive and Gramnegative bacteria [7].

Meanwhile, the routinely used clinical aminoglycosides have long been known to inhibit the protein synthesis in bacteria by promoting mistranslation to induce codon misreading on delivering the aminoacyl-transfer RNA [8]. However, like most antibiotics, aminoglycosides also exhibit antibacterial resistance in various forms, including enzymatic modification, target-site modification via an enzyme or chromosomal mutation, and efflux. To reduce AMR's susceptibility in aminoglycosides, a reduced dosage is desired, which would impact the antibacterial activity of the drug, and it remains a trade-off in resolving the AMR issue in aminoglycosides [9].

Despite its promising potential, studies on aminoglycoside loaded or immobilized on synthesized zeolite as an antibacterial agent remain scarce. To complement this trade-off, the present study hybridized aminoglycosides with zeolite matrix to reduce the required dose of aminoglycosides in suppressing various bacteria, including Gram-positive and Gram-negative bacteria. Therefore, this study aimed to evaluate the efficacy of antibacterial activities for a synthesized zeolite loaded with streptomycin (STR), which was the first approved aminoglycoside antibiotic. Also, zeolite had been successfully synthesized from kaolinite (KAO), in which the near 1:1 ratio of Si/Al in KAO yielded zeolite of high purity [12] via cocrystallization [11]. KAO is a good starting material for zeolite synthesis because of its stable property, and it is abundant in Malaysia and widely available at low cost.

\section{Materials and Method}

The KAO (KM40) sample was purchased from Kaolin (M) Sdn. Bhd. located at Tapah, Perak, Malaysia. In this study, the alkaline hydrothermal synthesis was used to produce zeolite A (ZEO), and the methodology was based on the published work of another study [10] with some modifications on the crystallization time and temperature. In ZEO production, plasticbased apparatus such as Teflon or polytetrafluoroethylene (PTFE) bottles were used to prevent the corrosion of glassware [13]. 


\subsection{Synthesis of zeolite A from natural kaolinite.}

KAO was converted to metakaolinite (MTK) via calcination at $900{ }^{\circ} \mathrm{C}$ for 2 hours using a muffle furnace (model: Carbolite ELF 11/6B/301). Subsequently, $5.0 \mathrm{~g}$ of MTK were mixed with $66.5 \mathrm{~mL}$ of $2.75 \mathrm{M} \mathrm{NaOH}$ solution and continuously stirred using a magnetic stirrer for 2 hours in silicon oil at $70{ }^{\circ} \mathrm{C}$.

The mixture was then left to age for 20 hours at room temperature, after which the mixture was allowed to crystallize at $100{ }^{\circ} \mathrm{C}$ for 24 hours in a universal oven (model: Memmert MMT-UN55). The white mixture was then filtered using Macherey-Nagel filter paper (125 $\mathrm{mm}$ ) and rinsed a few times with warm distilled water. The solid portion was dried overnight in an oven at $80{ }^{\circ} \mathrm{C}$. The dried solid sample was grounded using mortar and pestle and sieved into the powder form as ZEO. Finally, the powder sample was kept in a labeled clean container to be used for the drug loading experiment of streptomycin (STR) adsorption.

\subsection{Preparation of streptomycin immobilized zeolite A.}

The STR powder was purchased from Santa Cruz Biotechnology Inc., USA. The adsorption of STR on the synthesized ZEO encompassed three different STR concentrations, i.e., 50, 100, and $200 \mathrm{mg} / \mathrm{L}$. A 100-mL stock solution of STR was prepared for each concentration by dissolving the corresponding amount of STR powder in distilled water [14]. Each of these stock solutions of STR was added with $0.5 \mathrm{~g}$ of the synthesized zeolite, yielding three mixtures with 50, 100, and $200 \mathrm{mg} / \mathrm{L}$ STR. They were labeled as 50ZS, 100ZS, and 200ZS, respectively. Then, each of the mixtures was stirred using a magnetic stirrer for 24 hours. The mixture was filtered using a conventional filter paper to separate the solid portion of the mixture from the filtrate. The solid portion was dried overnight in an oven at $70{ }^{\circ} \mathrm{C}$. The recovered solid was grounded and sieved into powder form for further usage.

\subsection{The structural characterization of the materials.}

The crystallinity of the KAO, MTK, and synthesized ZEO was characterized using the X-ray Diffraction (XRD) recorded on a Bruker D8 Advance diffractometer with $\mathrm{Cu}-\mathrm{K} \alpha$ radiation $(\lambda=1.5406 \AA, 40 \mathrm{kV}, 20 \mathrm{~mA})$ within the $2 \theta$ range of $10^{\circ}-75^{\circ}$ and a scan step rate of $0.05^{\circ} \mathrm{s}^{-1}$. The grain size of ZEO was measured using Gatan view software (version, name of the software developer, country).

Fourier-Transform Infrared (FT-IR) spectroscopy was performed using an FT-IR spectrophotometer (model: Nicolet iS50 Thermo Scientific) to investigate the functional groups present in the samples, in which potassium bromide $(\mathrm{KBr})$ pellet was added to the sample at a sample: $\mathrm{KBr}$ ratio of 1: 10 to make pathlengths small, thus preventing over absorbance by the sample. The sample containing $\mathrm{KBr}$ was placed on the holder, and the FTIR analysis was performed with OMNIC software.

Besides, the surface morphology and elemental analysis was performed with the Field Emission Scanning Electron Microscopy (FESEM) via an electronic scanning microscope (model: JEOL JSM 6701-F) and coupled with the Energy Dispersive-X-ray (EDX) analyzer. Due to the samples' low electron conductivity, a platinum coating was used to produce optimized image quality.

Also, the Transmission Electron Microscopy (TEM) was carried out to analyze the twodimensional (2-D) morphology and particle size of the synthesized zeolite powder using a transmission electron microscope (model: Hitachi HT7700) at $120 \mathrm{kV}$. For TEM analysis, 
ethanol was used as the solvent to disperse the sample particles via sonication treatment, where the dispersed sample was then dropped onto a carbon grid.

A dispersion behavior study was conducted to investigate the changes in the inorganic zeolite's physical properties when adsorbed with the organic STR. Distilled water and n-hexane were used as the dispersion solvent, in which $0.05 \mathrm{~g}$ of the three mixtures of zeolite and STR (50ZS, 100ZS, and 200ZS) was added into a mixture of $3 \mathrm{~mL}$ distilled water and $3 \mathrm{~mL} \mathrm{n}$ hexane. The relative position of the samples in the mixture was compared using images at three conditions: (1) immediately after the sample was added, (2) after the mixture was shaken for 30 minutes at room temperature, and (3) 24 hours after the samples were left in a static condition.

\subsection{Antibacterial assay.}

The antibacterial activity of the investigated samples (pure ZEO, ZS50, ZS100, and ZS200) was evaluated against the Gram-positive bacteria Staphylococcus aureus (ATCC 6538) and the Gram-negative bacteria Escherichia coli (ATCC 11229). The qualitative and quantitative antibacterial activities of these samples were examined using the disc diffusion technique (DDT) and minimum inhibition concentration (MIC), respectively. The experiments were strictly performed under aseptic conditions to avoid contamination. For DDT assay, these four samples (ZEO, 50ZS, 100ZS, and 200ZS), $0.2 \mathrm{~g}$ each, was pressed into a pellet using a hydraulic press (model: E-Z Press ${ }^{\mathrm{TM}}$, International Crystal Laboratories, United States) at a pressure of $1400 \mathrm{psi}$. The bacteria were cultured on nutrient agar (NA) plates at $37^{\circ} \mathrm{C}$ for 24 hours. Approximately five to ten colonies of the cultured bacteria were inoculated in sterilized $0.9 \%$ saline solution. The suspension was adjusted to $0.5 \mathrm{McFarland}$ standards $\left(1.5 \times 10^{8}\right.$ Colony Forming Unit, or CFU). The sterile cotton swab was used to inoculate NA plates' surface by turning the plate every $60^{\circ}$ to ensure homogenous bacteria growth. The sample pellet disc was placed on the surface of the agar plates gently at equal distances. The diameter of inhibition (in $\mathrm{cm}$ ) was measured using a ruler after 24-hour incubation at $37^{\circ} \mathrm{C}$.

The MIC technique is an assay for testing the lowest concentration of antibacterial agent to inhibit bacterial growth completely. Briefly, $10 \%(\mathrm{v} / \mathrm{v})$ of the bacteria culture was transferred in $180 \mathrm{~mL}$ of fresh LB and was shaken at an agitation rate of $200 \mathrm{rpm}$ at $37^{\circ} \mathrm{C}$ until the $\mathrm{OD}$ at $550 \mathrm{~nm}$ reaching the range of $0.6-0.8$. Then, the bacteria were transferred into Falcon tubes and centrifuged at $4000 \mathrm{rpm}$ for 15 minutes, and the pellet was washed three times with sterile distilled water and $0.9 \%$ saline solution. The pellet was then suspended in either $10.0 \mathrm{~mL}$ of saline or distilled water to prepare nine different concentration ranges of the sample $(0.05,0.1$, $0.5,1.0,3.0,6.0,9.0$, and $12.0 \mathrm{~g} / \mathrm{L}$ ) for each of the four samples in which $10 \mathrm{~mL}$ bacterial suspension were added into each concentration. All samples were shaken for 30 minutes with an agitation rate of $100 \mathrm{rpm}$ at $37^{\circ} \mathrm{C}$, after which $10 \mu \mathrm{L}$ of the bacteria solution was pipetted onto the NA, and the plate was incubated at $37{ }^{\circ} \mathrm{C}$ for 16 hours. The plate was observed for bacterial growth. Finally, the STR solution disc $(10 \mathrm{mg} / \mathrm{L})$ was used as the positive control. The paper disc soaked with distilled water served as the negative control for each experimental set of E. coli and S. aureus. 


\section{Results and Discussion}

\subsection{The structural characterization.}

Figure 1(a) shows the X-ray diffractograms for KAO, MTK, and synthesized ZEO, with strong peaks at $12.34^{\circ}$ and $24.64^{\circ}$ for $\mathrm{KAO}$ [7] and minor traces of quartz at $26.68^{\circ}$ for raw KAO [15]. Quartz is one of the common impurities found in natural clays, including the Malaysian clays, due to weathering and natural decomposition of minerals [15]. However, quartz could potentially cause inflammation to the skin when exposed to a high quartz concentration, which is thus an undesirable constituent for applying antibiotics. Therefore, further crystallization and purification of KAO into ZEO was needed. Meanwhile, MTK could be identified by the absence of XRD peaks, indicating the amorphous form of MTK. The formation of the amorphous phase was attributable to the decomposition of KAO at the high temperature of $900{ }^{\circ} \mathrm{C}$, promoting the structural change of KAO. Nevertheless, the formation of high-reactivity MTK was indispensable because it was a transitional step in the KAO-toZEO synthesis pathway [12].

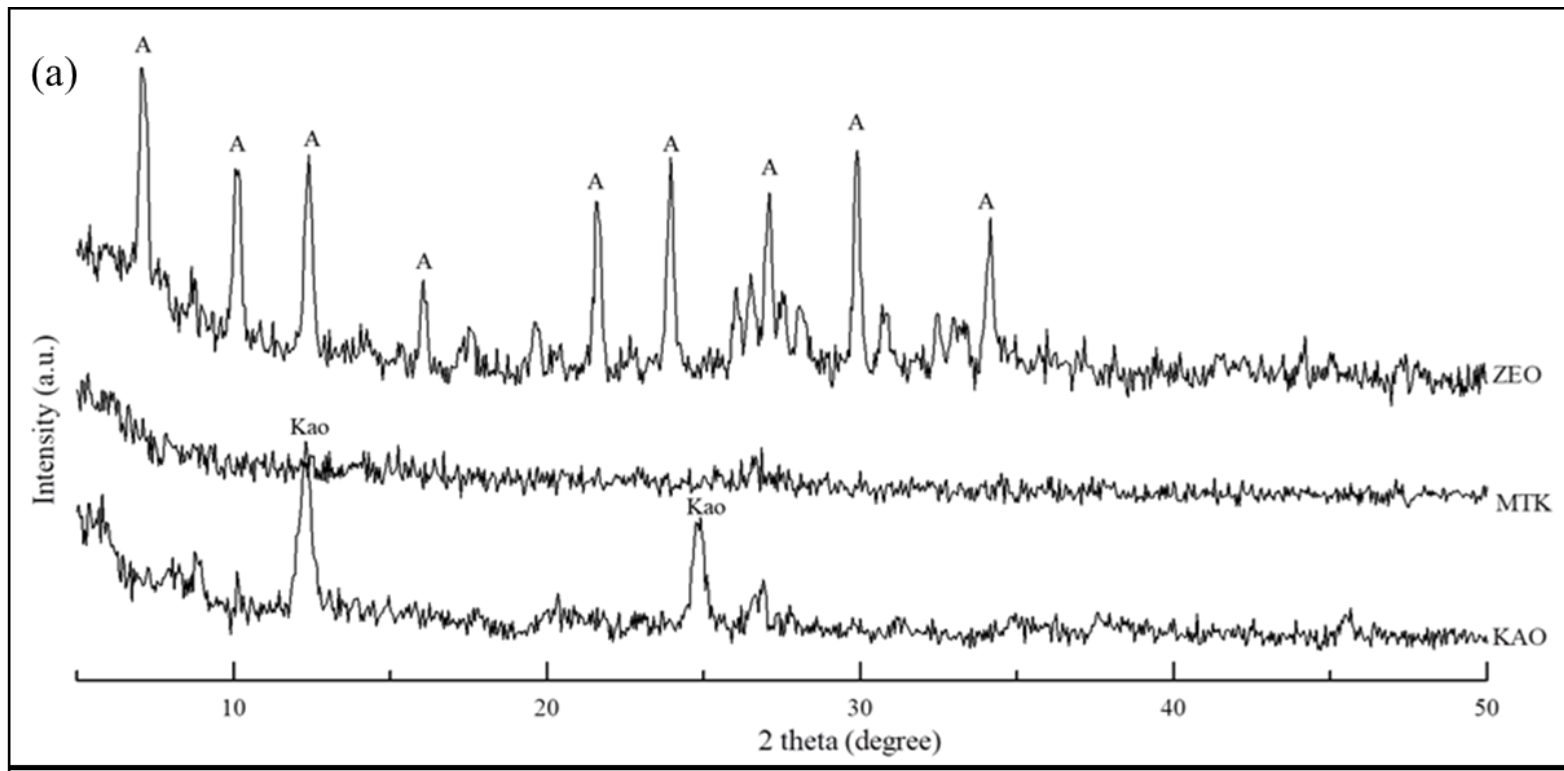

(b)

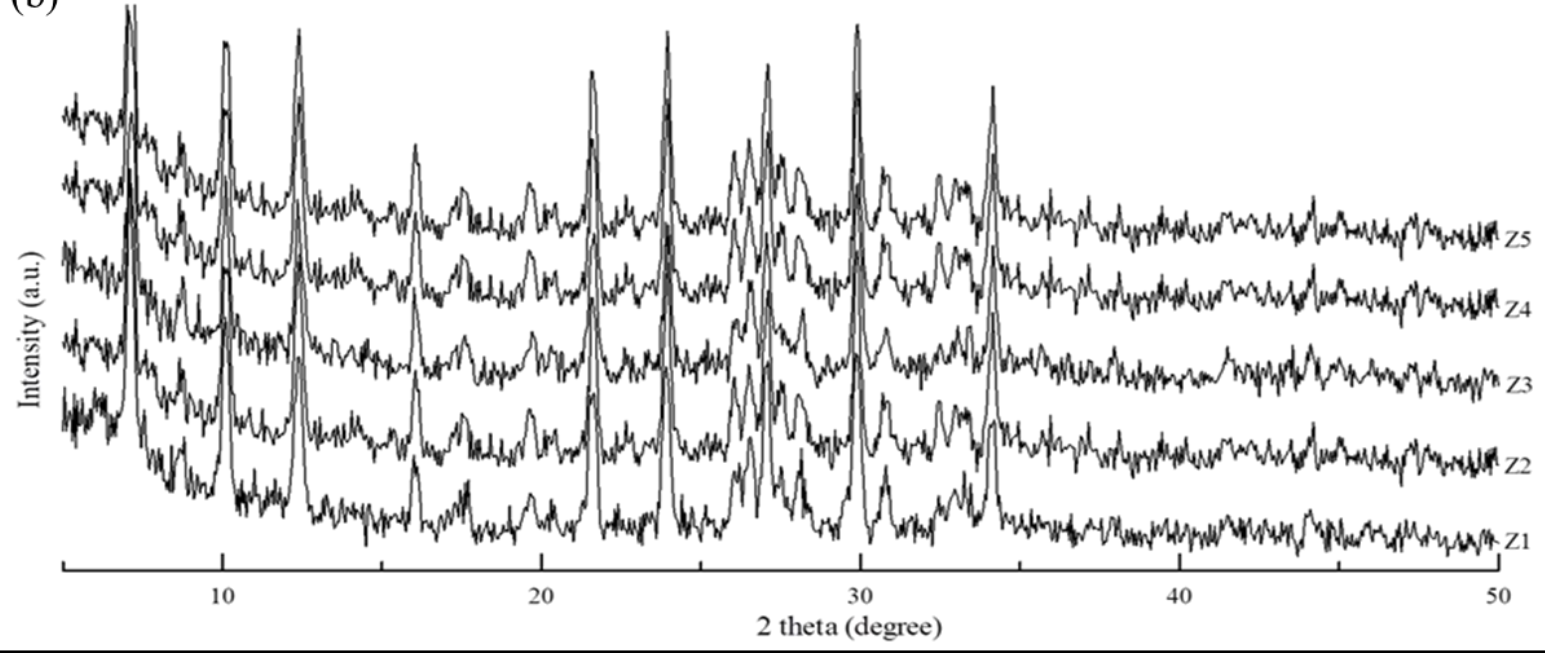

Figure 1. (a) XRD diffractogram of kaolinite (KAO), metakaolinite (MTK) and synthesized zeolite A (ZEO) with important peaks of zeolite A (Legend: A: Zeolite A, Kao: Kaolinite) (b) XRD diffractogram of samples from different batches of synthesized zeolites (Z1-Z5). 
The formation of synthesized ZEO was confirmed by comparing the nine pronounced peaks obtained in this study with the XRD pattern of sodium aluminum hydrate zeolite A [14]. The nine peaks in this study were identified at $2 \theta=7.13^{\circ}, 10.12^{\circ}, 12.40^{\circ}, 16.20^{\circ}, 21.63^{\circ}, 23.94^{\circ}$, $27.08^{\circ}, 29.90^{\circ}$, and $34.14^{\circ}$, and they matched well with the theoretical XRD peaks of ZEO. Meanwhile, the quartz peak's disappearance from the XRD pattern of ZEO suggested that the synthesized ZEO showed a high degree of purity. Figure 1(b) shows the XRD pattern without the quartz peak for five batches of ZEO repeatedly synthesized using the same method, suggesting high reproducibility of the hydrothermal synthesis technique for synthesizing ZEO from natural kaolinite.

In the drug loading experiment, no new XRD peak was identified in the immobilization of STR molecules on ZEO. The adsorption of STR molecules was most likely limited to the surface of ZEO because ZEO has a closely-packed and rigid framework structure with very low porosity, making it hard for large ions to occupy the atomic space within the zeolite framework [16]. Indeed, the structural stability of ZEO remained unchanged despite the immobilization of STR.

The FT-IR spectra also supported the transformation of KAO to ZEO in the fingerprint region of $1100-450 \mathrm{~cm}^{-1}$ and hydroxyl stretching region from 3000 to $3900 \mathrm{~cm}^{-1}$. Figure 2 shows the FT-IR spectra for KAO, MTK, and ZEO samples with pronounced peaks for several important bonds, such as $\mathrm{Si}-\mathrm{O}, \mathrm{Al}-\mathrm{OH}$, and $\mathrm{OH}$ related to the transformation KAO to ZEO. The raw KAO had a well-defined spectrum in this region due to $\mathrm{Si}-\mathrm{O}, \mathrm{Si}-\mathrm{O}-\mathrm{Al}$, and $\mathrm{Al}-\mathrm{OH}$ vibrations. As for MTK, upon calcination at $900{ }^{\circ} \mathrm{C}$, most of the bonds were disrupted, indicating an amorphous state in the FT-IR spectrum. However, a small peak at $550 \mathrm{~cm}^{-1}$ indicated the ionic Si-O-Si bond's presence, which was difficult to be broken as compared to another ionic bond, such as the Al-OH bond with no peak at $910 \mathrm{~cm}^{-1}$ (disrupted) in the FT-IR. On the contrary, distinct peaks were observed at 650 and $1000 \mathrm{~cm}^{-1}$, indicating strong Si-O bonds.

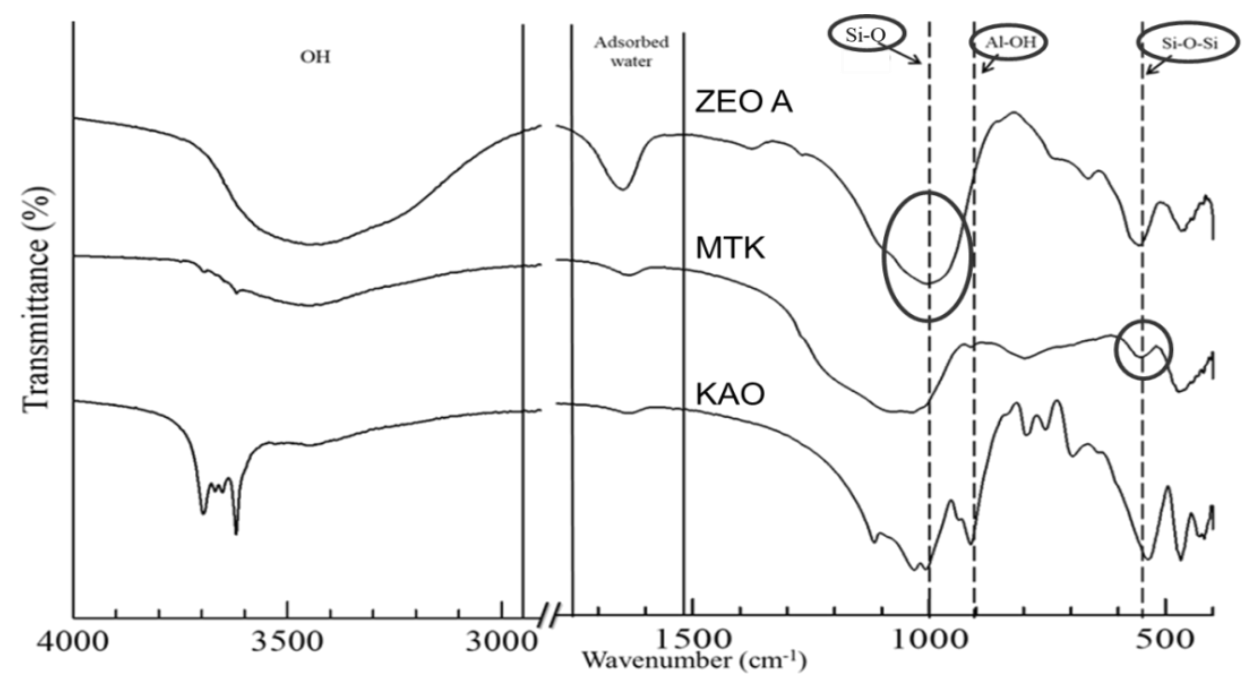

Figure 2. FTIR spectra of KAO, MTK, and ZEO.

Figure 3 shows the consistent pattern of FT-IR spectra of ZEO with varying peak intensities in the fingerprint region between 1800 and $400 \mathrm{~cm}^{-1}$ and hydroxyl stretching region from 3000 to $3800 \mathrm{~cm}^{-1}$. The peaks at 650,548 , and $456 \mathrm{~cm}^{-1}$ indicated the presence of ZEO [18]. The peak at $548 \mathrm{~cm}^{-1}$ indicated the vibration of the four tetrahedral double rings (D4R), which was dominant in the secondary building unit of the ZEO structure, and the peak at 456 
$\mathrm{cm}^{-1}$ was probably the result of internal vibration of D4R. These four signature peaks did not change in terms of intensity and peak position for all samples, suggesting that the cubic structure of ZEO was fairly well maintained with all functionalized zeolite. Meanwhile, the peak at $1636 \mathrm{~cm}^{-1}$ was attributable to the hydration of water. Taken together, the presence of ZEO was confirmed at the peak of $1000 \mathrm{~cm}^{-1}$, which signified ample bonds of Si-O [17], and the FT-IR spectrum of the synthesized ZEO matched with the characteristic peak of hydrated ZEO.

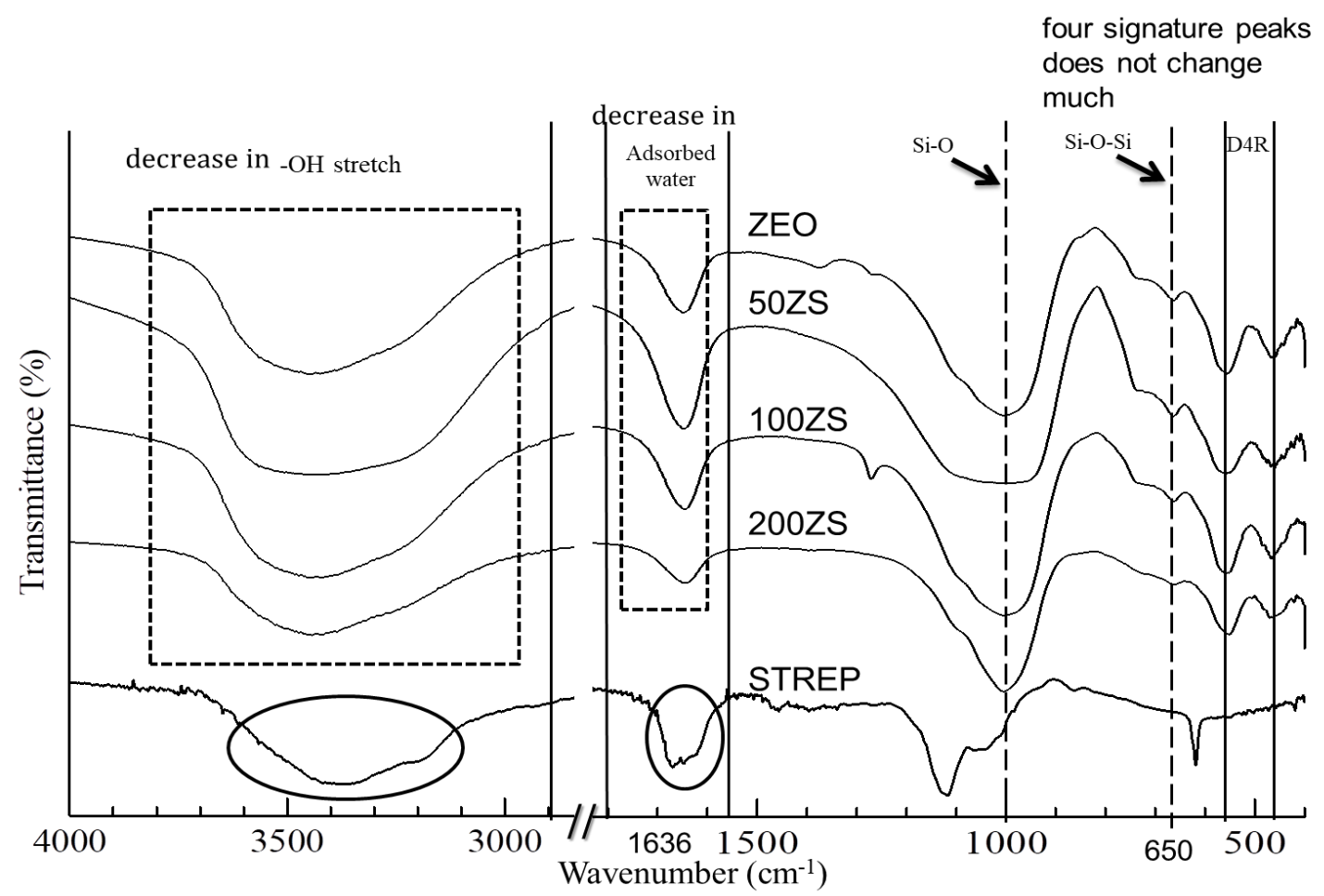

Figure 3. FTIR spectra of ZEO, 50ZS, 100ZS, 200ZS, and streptomycin sulfate.

As the concentration of STR-loaded to zeolite increased (ZEO < 50ZS < 100ZS < 200ZS), both the intensity of hydroxyl stretching from 3000 to $3800 \mathrm{~cm}^{-1}$ and the adsorbed water at peak $1636 \mathrm{~cm}^{-1}$ decreased. These peaks overlapped with the important $-\mathrm{NH}$ peaks of STR, which could be seen at $1650 \mathrm{~cm}^{-1}$ [19]. The FT-IR spectra showed that the loading of STR onto the synthesized ZEO did not show any distinctive peaks due to the presence of similar groups, such as $-\mathrm{OH}$ and $-\mathrm{NH}$ in ZEO. In other words, the stronger peak of hydrogen bonds and the inter-hydrogen bonds formed among the cationic antibiotic might have suppressed the FT-IR peaks of STR molecules. Thus, the reduced intensity of the overlapped peaks could be indicative that ZEO was successfully loaded with STR molecules.

Figure 4 shows the surface morphology of KAO, MTK, ZEO, and STR-loaded ZEO (ZS samples) via FESEM analysis, and KAO could be observed by its characteristic platy morphology and thick book stack-like structures [20]. In contrast, ZEO showed the distinct morphology of cubic crystals with sharp edges. Figure 4 displays the presence of intergrowth twinning interpenetrating the face of ZEO crystal onto its cubic shape with a negligibly low amount of amorphous and aggregate materials (impurities). Such a structural feature happened due to the stacking faults at the sodalite cage at the early nucleation stage [21]. The twin growth was also commonly observed in fluorite crystals [22]. The ZEO crystals synthesized in this study had particle sizes ranging from $6-8 \mathrm{~nm}$, which were comparatively smaller than $50 \mathrm{~nm}$ reported in a previous study [23]. The smaller particle size obtained in this study was probably 
due to the 20 -hour aging before $100{ }^{\circ} \mathrm{C}$ crystallization stage. The synthesized ZEO was then loaded with STR. Figure 4 shows the deposition of STR particles on the ZEO surface, but the relatively large STR particles were unable to penetrate the internal pores of ZEO, which were usually in the range of $0.3-1.0 \mathrm{~nm}$ in size [22]. Overall, there were apparent morphological changes from the raw KAO to the cubic ZEO, suggesting a successful synthesis of ZEO crystal with little impurity.

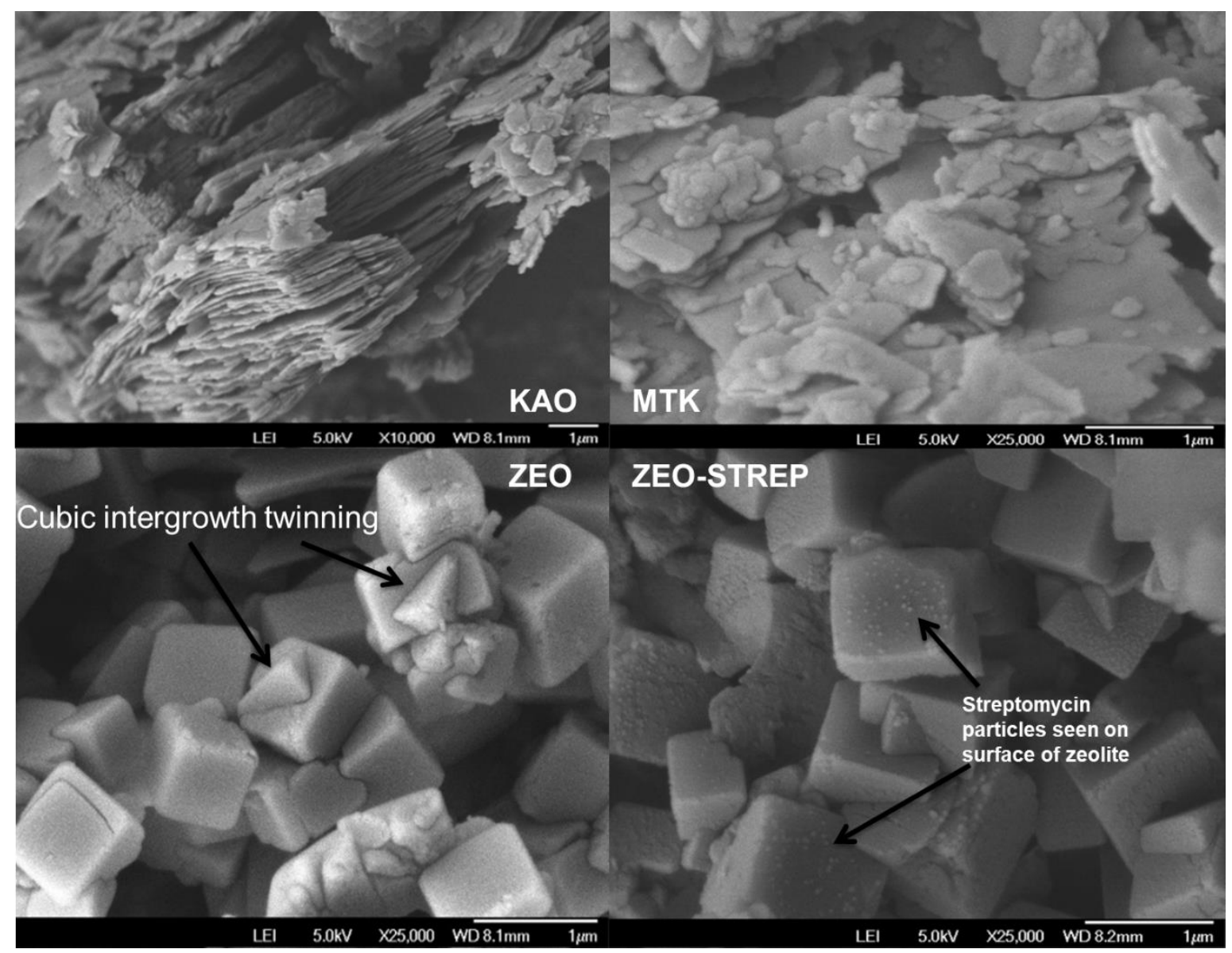

Figure 4. FESEM micrographs showing KAO, MTK ZEO and ZEO-STREP.

Figure 5 shows the regular TEM pattern of ZEO, indicating its high crystallinity structure, and this result aligned well with the sharp XRD peaks for the crystalline structure of ZEO in Figure 1. This study's ZEO grain size ranged from $6-8 \mathrm{~nm}$, which were comparatively smaller than the range of $50 \mathrm{~nm}$ reported in another study [23]. The smaller grain size increased the ZEO surface's susceptibility for STR loading and antibacterial activities [24]. Also, Figure 5 shows the pattern of selected area diffraction (SAED) for the synthesized zeolite sample in the cubic formation of $\left[\begin{array}{lll}1 & 0 & 0\end{array}\right]$ and $\left[\begin{array}{lll}1 & 0 & 0\end{array}\right]$ with a regular single crystal, confirming that only ZEO (A-type) was synthesized without any major impurities.

The adsorption of foreign molecules, especially organic molecules, would affect the surface phenomena of the ZEO. In studying KAO, MTK, ZEO's dispersion behavior in the aqueous and hexane media, Figure 6 shows that the STR-immobilised zeolite (ZS samples) were more hydrophobic compared to individual KAO, ZEO, and STR. This analysis showed that the surface alteration in zeolite could increase its hydrophobicity. 


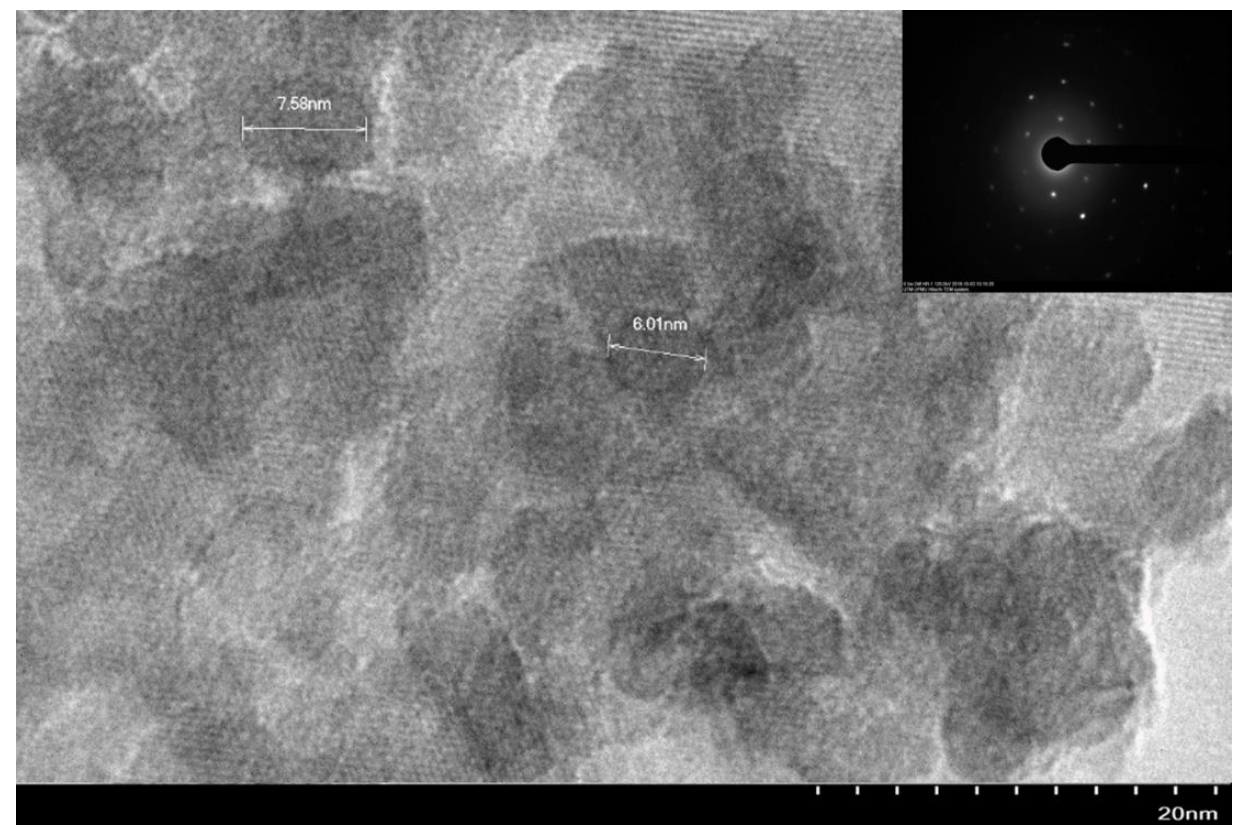

Figure 5. Transmission electron microscopy (TEM) image of synthesized zeolite with selected area electron diffraction (SAED) pattern of ZEO-STREP.

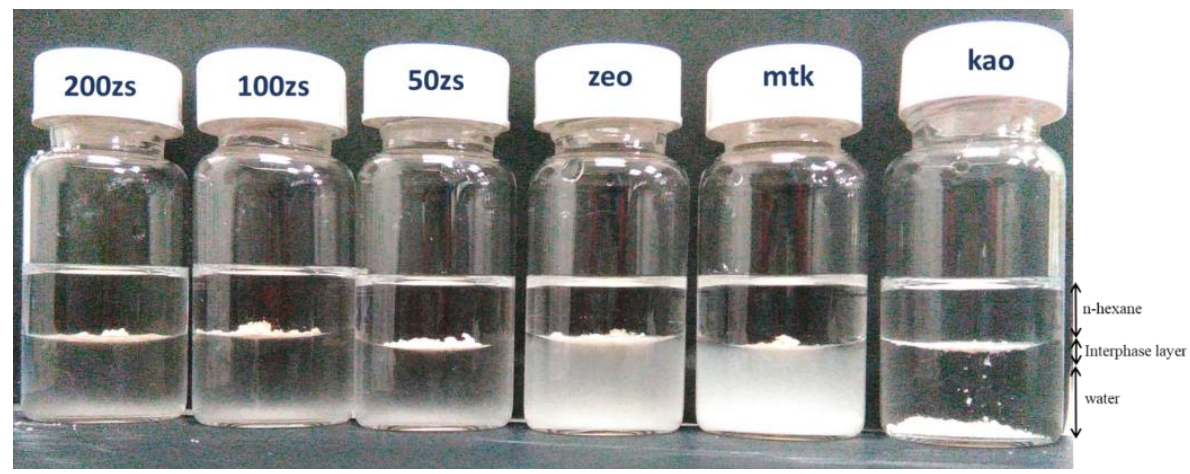

Figure 6. Dispersion behavior of samples in the hexane-water mixture.

The synthesis products of zeolite A from Malaysian local kaolinite minerals were successfully characterized using XRD, FTIR, FESEM, EDX, TEM, and dispersion behavior. The synthesized product contains high crystallinity of zeolite A with a smaller particle size of 6 to $8 \mathrm{~nm}$. Despite rigid structure with small internal pores, adsorption of antibiotic streptomycin was achieved on zeolite surfaces without any structural changes. Meanwhile, the FESEM micrographs show the cubic structure zeolite A's expected morphology formation with visible streptomycin particles on its surface. The TEM result highlights that the synthesized zeolite has single crystal composition of zeolite A and hence, further justified that the product has negligible impurities. The nature of streptomycin loaded zeolite A changed from hydrophilic to hydrophobic due to its adsorption on its surface, making it favorable for antibacterial activity.

\subsection{Antibacterial activity.}

The samples' antibacterial assay was conducted against Gram-negative bacteria (E. coli ATCC 11229) and Gram-positive bacteria (S. aureus ATCC 6538) through DDT and MIC techniques. These two bacteria represent commonly found bacteria in wastewater and prone to cause infections to humans [25]. Streptomycin-loaded zeolite was prepared in three concentrations (50, 100, and $200 \mathrm{mg} / \mathrm{L}$ ) and compared with control samples. Streptomycin 
solution disc $(10 \mathrm{mg} / \mathrm{L})$ was used as the positive control, while paper disc soaked with distilled water is used as the negative control for each experimental set of E. coli and S. aureus.

Figure 7(a) and (b) show the inhibition zone's images formed around the sample pellets on bacteria plates. This result proves successful diffusion of streptomycin onto the media containing bacteria. The inhibition zone of the 200ZS disc was the biggest for both bacteria, followed by 100ZS and finally, 50ZS. As the concentration of streptomycin increases, the inhibition zone's size also increases, showing increased antibacterial effect effectiveness.

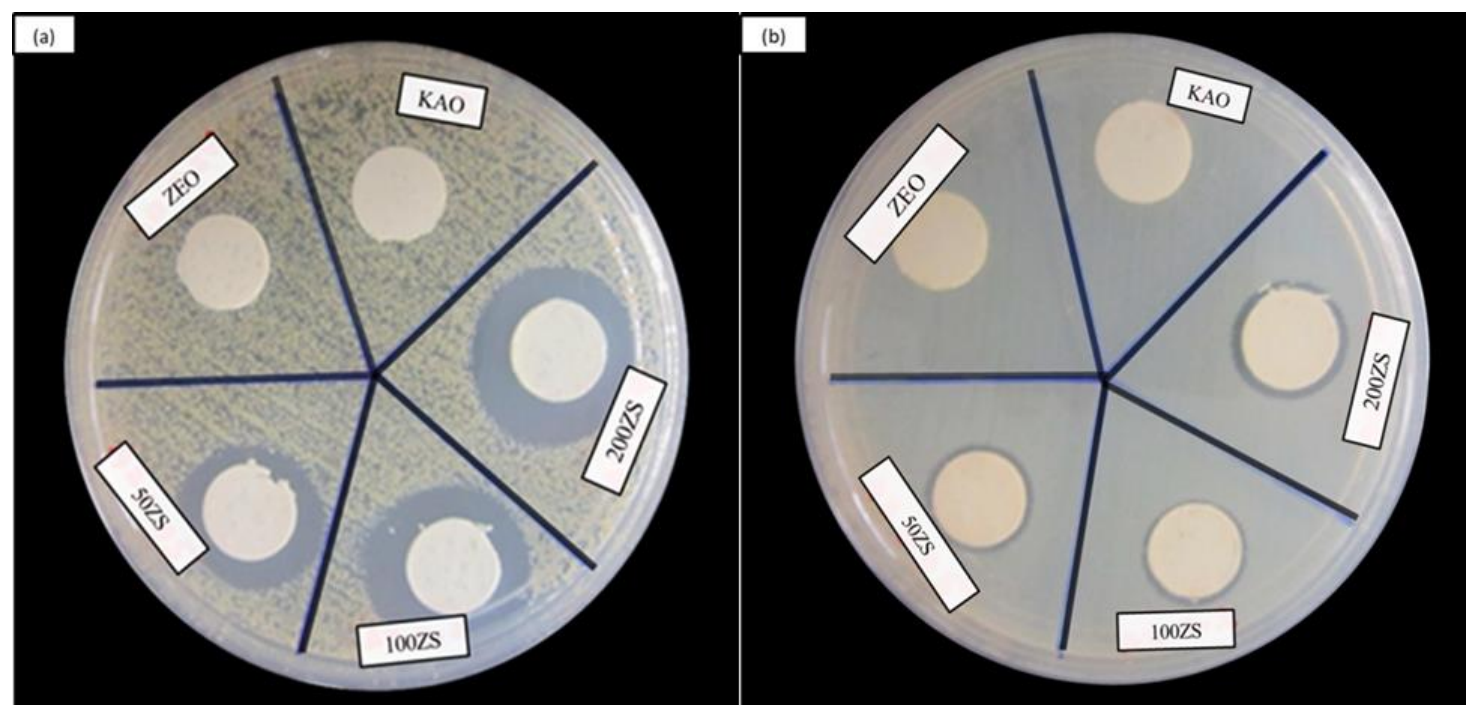

Figure 7. The images of the plate from DDT against (a) S. aureus ATCC 6538 and (b) E. coli ATCC 11229.

The inhibition zone values for $S$. aureus and E. coli are shown in Table 1. Table 1 shows that the inhibition zones for $S$. aureus are slightly bigger than $E$. coli for all streptomycinloaded zeolite samples. Inhibition zones as large as 2.02 and $2.36 \mathrm{~cm}$ against Gram-positive and Gram-negative bacteria, respectively, are obtained from 200ZS samples. Streptomycin works well on both bacteria but slightly higher inhibitory effect towards Gram-positive bacteria. This might be due to the difference in cell wall composition where Gram-positive bacteria have a thick peptidoglycan layer, whereas Gram-negative bacteria possess a complex outer membrane layer, which could act as a selective barrier for any antibacterial compound [26]. Hence, Gram-positive bacteria are proven more susceptible towards streptomycin loaded synthesized zeolite as compared to Gram-negative bacteria.

Table 1. Inhibition zone diameter of the samples against bacteria.

\begin{tabular}{l|c|c}
\multirow{2}{*}{ Samples } & \multicolumn{2}{|c}{ Inhibition zone (cm) } \\
\cline { 2 - 3 } & E. coli (Gram-negative) & S. aureus (Gram-positive) \\
\hline STR & 2.13 & 2.41 \\
\hline KAO & 0.00 & 0.00 \\
\hline ZEO & 0.00 & 0.00 \\
\hline $\mathbf{5 0 Z S}$ & 1.60 & 2.04 \\
\hline $\mathbf{1 0 0 Z S}$ & 1.87 & 2.20 \\
\hline $\mathbf{2 0 0 Z S}$ & 2.02 & 2.36
\end{tabular}

The antibacterial efficacy of zeolite loaded with streptomycin can be attributed to the electrostatic adsorption of polycationic streptomycin to the negatively charged component of the bacteria's phospholipid membrane, as shown in Figure 8. Magnesium ions' displacement follows this to enhance permeability and increase antibiotic uptake into the cell [27]. Once into the cell, the streptomycin molecule attacks the ribosome causing mistranslated proteins to form. Hence, this consequently leads to the cytoplasmic membrane damage that further facilitates 
subsequent streptomycin entry. The rapid uptake of additional aminoglycosides into the cytoplasm has caused an increased inhibition of protein synthesis and mistranslation and, therefore, accelerates cell death [28]. In an alternative point of view, there could also be a hydrophobic attraction between functionalized zeolite and the lipophilic components of bacterial cell walls, such as the phospholipids of Gram-positive and the phospholipids and lipopolysaccharide (LPS) of Gram-negative bacteria. The hydrophobic attraction also accelerates the action of streptomycin upon contact with bacteria [29]. The higher the concentration of streptomycin used, the bigger the inhibition zone due to the bacterial cell death.

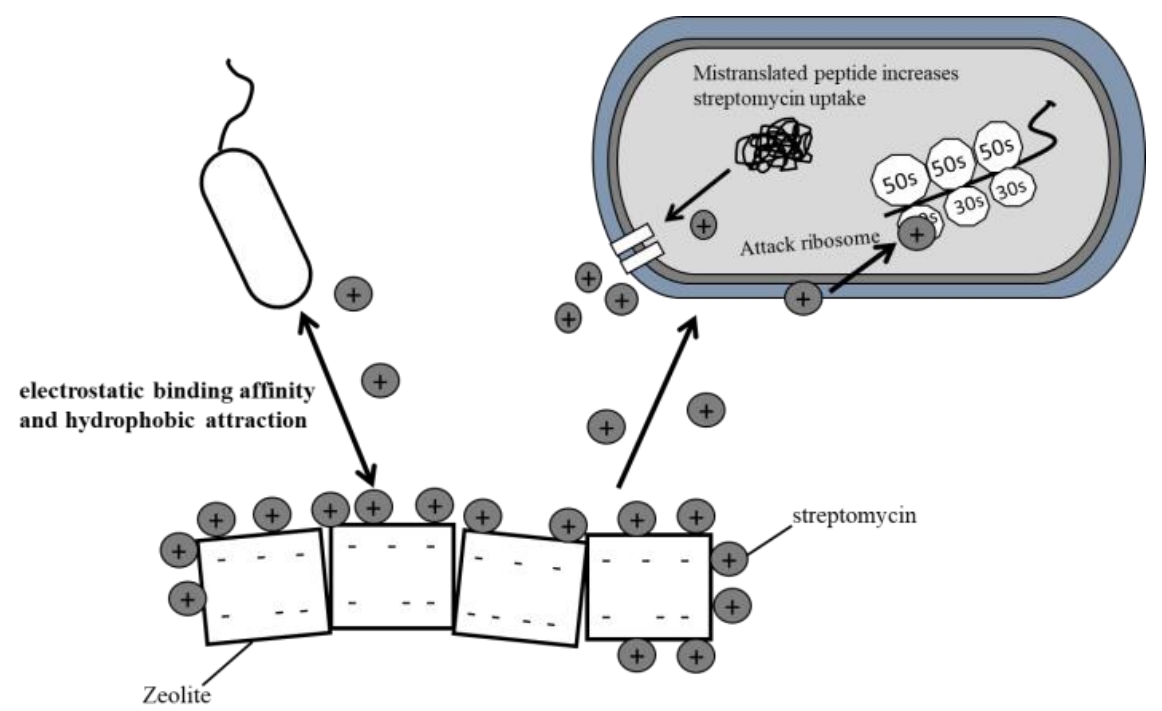

Figure 8. Possible mechanism of antibacterial action of streptomycin antibiotic immobilized on synthesized zeolite.

MIC was tested to determine the lowest antibacterial agent's lowest concentration to inhibit bacterial multiplication, reproduction, and growth. As a broad-spectrum drug, streptomycin was used as a positive control in this study to show that the antibiotic has high susceptibility towards both types of bacteria [30]. Both types of bacteria were susceptible to the modified zeolite with the lowest MIC value for Gram-negative bacteria at $3.0 \mathrm{~g} / \mathrm{L}$ in distilled water, as shown from Table 2. Besides that, the antibacterial activity of streptomycin loaded zeolite is directly proportional to the concentration of streptomycin used.

In general, the antibacterial activity of STR was better in distilled water compared to saline water, probably because of a stronger polarity for the STR molecules in water, and the $\mathrm{Cl}$ - ions in the saline would exert a chelating effect on STR, rending it less efficient in antibacterial activity [31].

Table 2. MIC values of samples against Gram-positive bacteria and Gram-negative bacteria in distilled water and $0.9 \%$ saline solution at $30 \mathrm{~min}$ incubation periods.

\begin{tabular}{l|c|c|c|c}
\multirow{2}{*}{ Samples } & MIC value $(\mathbf{g} / \mathbf{L})$ in $\mathbf{0 . 9 \%}$ saline solution & \multicolumn{2}{c}{ MIC value $(\mathbf{g} / \mathbf{L})$ in distilled water } \\
\cline { 2 - 5 } & $\boldsymbol{E}$ c coli & S. aureus & E. coli & S. aureus \\
\hline STR & 0.5 & 1 & 0.5 & 1 \\
\hline ZEO & $>12$ & $>12$ & $>12$ & $>12$ \\
\hline $\mathbf{5 0 Z S}$ & $>12$ & $>12$ & 12 & 9 \\
\hline $\mathbf{1 0 0 Z S}$ & 12 & $>12$ & 6 & 6
\end{tabular}

Nevertheless, a salty medium would effectively inhibit bacteria's growth; a hypertonic environment would cause the bacteria to lose water and eventually kill them [32]. In general, 
the antibacterial activity of STR would be most efficient at the alkaline $\mathrm{pH}$ of about 8 to 9, but the $\mathrm{pH}$ of the $0.9 \%$ saline solution used in this study was 5.5 (acidic), thereby reducing the efficiency of the antibacterial action of STR [33].

To benchmark the antibacterial of STR against other materials, this study also compared the MIC values of ZS samples with the reported clay-based composites in the works of literature for their antibacterial actions against Gram-positive and Gram-negative bacteria in both distilled water and $0.9 \%$ saline solution. As summarised in Table 3, ZS composites showed favorable MIC values, i.e., with better antibacterial effect, when compared against other clay-based composites, such as silver-kaolinite, silver-sodium adamsite ( $\mathrm{NaY}$ ) zeolite, and graphene oxide-zeolite, although these materials had different antibacterial mechanisms [34,35], and further studies would be needed to understand better the difference in the antibacterial actions of these materials.

Table 3. Benchmarking of MIC values of this study against previously-reported studies.

\begin{tabular}{l|c|c|c|c|c}
\multirow{2}{*}{ Materials } & \multicolumn{2}{|c|}{$\begin{array}{c}\text { MIC value }(\mathrm{g} / \mathrm{L}) \text { in } \mathbf{0 . 9 \%} \\
\text { saline solution }\end{array}$} & \multicolumn{2}{c|}{$\begin{array}{c}\text { MIC value }(\mathrm{g} / \mathbf{L}) \text { in } \\
\text { distilled water }\end{array}$} & \multirow{2}{*}{ References } \\
\cline { 2 - 5 } & E. coli & S. aureus & E. coli & S. aureus & \\
\hline Streptomycin-Zeolite & 6 & 9 & 3 & 6 & This work \\
\hline Silver-Kaolinite & 8 & $>14$ & $>10$ & $>10$ & {$[36]$} \\
\hline Silver-NaY Zeolite & 0.4 & 4 & 4 & 6 & {$[37]$} \\
\hline Graphene Oxide-Zeolite & - & - & 7 & 5 & {$[38]$}
\end{tabular}

\section{Conclusions}

ZEO was successfully synthesized from raw Malaysian KAO via the alkaline hydrothermal process with high reproducibility. The synthesized ZEO was loaded with three concentrations of aminoglycoside STR $(50,100$, and $200 \mathrm{mg} / \mathrm{L})$. The nanoporous ZEO with particle sizes of 6 to $8 \mathrm{~nm}$ had a high crystallinity structure and stable surface adsorption capacity toward STR without any structural changes. MIC values were as low as $3.0 \mathrm{~g} / \mathrm{L}$, with an inhibition zone of $2.36 \mathrm{~cm}$. ZS's favorable antibacterial properties made it a promising antibacterial agent since the raw material used in this study (KAO) was abundant, and the ZEO synthesis was highly reproducible at a low cost.

\section{Funding}

This research received funding from Fundamental Research Grant Scheme (FRGS) (Vot No 4F967).

\section{Acknowledgments}

The authors would like to thank the Malaysian Ministry of Education and Universiti Teknologi Malaysia for financial support under the Fundamental Research Grant Scheme (FRGS) (Vot No 4F967).

\section{Conflicts of Interest}

The authors declare no conflict of interest.

\section{References}

1. Theuretzbacher, U.; Bush, K.; Harbarth, S.; Paul, M.; Rex, J.H.; Tacconelli, E.; Thwaites, G.E. Critical analysis of antibacterial agents in clinical development. Nature Reviews Microbiology 2020, 18, 286-298, https://doi.org/10.1038/s41579-020-0340-0. 
2. Pidot, S.J.; Gao, W.; Buultjens, A.H.; Monk, I.R.; Guerillot, R.; Carter, G.P.; Lee, J.Y.H.; Lam, M.M.C.; Grayson, M.L.; Ballard, S.A.; Mahony, A.A.; Grabsch, E.A.; Kotsanas, D.; Korman, T.M.; Coombs, G.W.; Robinson, J.O; Gonçalves da Silva, A.; Seemann, T.; Howden, B.P.; Johnson, P.D.R.; Stinear, T.P. Increasing tolerance of hospital Enterococcus faecium to handwash alcohols. Sci. Transl. Med. 2018, 10, https://doi.org/10.1126/scitranslmed.aar6115.

3. Nadeem, S.F.; Gohar, U.F.; Tahir, S.F.; Mukhtar, H.; Pornpukdeewattana, S.; Nukthamna, P.; Moula Ali, A.M.; Bavisetty, S.C.B.; Massa, S. Antimicrobial resistance: more than 70 years of war between humans and bacteria. Critical Reviews in Microbiology 2020, 46, 578-599, https://doi.org/10.1080/1040841X.2020.1813687.

4. World Health Organization. 2019 antibacterial agents in clinical development: an analysis of the antibacterial clinical development pipeline.

https://apps.who.int/iris/bitstream/handle/10665/330420/9789240000193-eng.pdf.

5. Morrison, K.D.; Misra, R.; Williams, L.B. Unearthing the Antibacterial Mechanism of Medicinal Clay: A Geochemical Approach to Combating Antibiotic Resistance. Scientific Reports 2016, 6, https://doi.org/10.1038/srep19043.

6. Dutta, P.; Wang, B. Zeolite-supported silver as antimicrobial agents. Coordination Chemistry Reviews 2019, 383, 1-29, https://doi.org/10.1016/j.ccr.2018.12.014.

7. Rios, C.; Williams, C.; Castellanos, O. Synthesis of zeolite LTA from thermally treated kaolinite. Revista Facultad de Ingeniería Universidad de Antioquia 2010, 53, 30-41.

8. Krause, K.M.; Serio, A.W.; Kane, T.R.; Connolly, L.E. Aminoglycosides: An Overview. Cold Spring Harbor perspectives in medicine 2016, 6, https://doi.org/10.1101/cshperspect.a027029.

9. Mingeot-Leclercq, M.-P.; Glupczynski, Y.; Tulkens, P.M. Aminoglycosides: Activity and Resistance. Antimicrobial Agents and Chemotherapy 1999, 43, 727-737, https://doi.org/10.1128/aac.43.4.727.

10. Ishak, S.N.; Malek, N.A.N.N.; Yusop, Z.; Williams, C.D.; Suhartono, S.; Syafiuddin, A. Evaluation of phase transformation behaviors of zeolite and antibacterial properties against Gram-positive and -negative bacteria. Journal of the Chinese Chemical Society 2020, 67, 2042-2049, https://doi.org/10.1002/jccs.202000046.

11. Youssef, H.F.; Hegazy, W.H.; Abo-Almaged, H.H. Preparation and characterization of micronized zeolite Na-A: cytotoxic activity of silver exchanged form. J. Porous Mater. 2015, 22, 1033-1041.

12. Johnson, E.B.G.; Arshad, S.E. Hydrothermally synthesized zeolites based on kaolinite: a review. Appl. Clay Sci. 2014, 97, 215-221, https://doi.org/10.1016/j.clay.2014.06.005.

13. Yusof, A.M.; Nizam, N.A.; Abd Rashid, N.A. Hydrothermal conversion of rice husk ash to faujasite-types and NaA-type of zeolites. J. Porous Mater. 2010, 17, 39-47.

14. Aziz, M.; Ahmad Nizam Nik Malek, N.; Ishak, S.; Asraf, M.; Abdul Hadi, A.; Awaluddin, M. Simultaneous action of surfactant modified clinoptilolite: Adsorbent of dyes and antibacterial agent. Malaysian Journal of Fundamental and Applied Sciences 2018, 14, 477-481, https://doi.org/10.11113/mjfas.v14n0.1283.

15. Chin, C.L.; Ahmad, Z.A.; Sow, S.S. Relationship between the thermal behaviour of the clays and their mineralogical and chemical composition: Example of Ipoh, Kuala Rompin and Mersing (Malaysia). Applied Clay Science 2017, 143, 327-335, https://doi.org/10.1016/j.clay.2017.03.037.

16. Jha, B.; Singh, D.N. Basics of zeolites. In: Fly Ash Zeolites. Springer, Singapore. 2016; pp. 5-31, https://doi.org/10.1007/978-981-10-1404-8_2.

17. Gougazeh, M.; Buhl, J.C. Synthesis and characterization of zeolite A by hydrothermal transformation of natural Jordanian kaolin. Journal of the Association of Arab Universities for Basic and Applied Sciences 2014, 15, 35-42, https://doi.org/10.1016/j.jaubas.2013.03.007.

18. Meanwell, R.J.L.; Shama, G. Direct FTIR Assay of Streptomycin in Agar. Biotechnology Letters 2005, 27, 1629-1631, https://doi.org/10.1007/s10529-005-2604-1.

19. Irfan Khan, M.; Khan, H.U.; Azizli, K.; Sufian, S.; Man, Z.; Siyal, A.A.; Muhammad, N.; Faiz ur Rehman, M. The pyrolysis kinetics of the conversion of Malaysian kaolin to metakaolin. Applied Clay Science 2017, 146, 152-161, https://doi.org/10.1016/j.clay.2017.05.017.

20. Porcher, F.; Dusausoy, Y.; Souhassou, M.; Lecomte, C. Epitaxial growth of zeolite X on zeolite A and twinning in zeolite A: Structural and topological analysis. Mineralogical Magazine - MINER MAG 2000, 64, 1-8, https://doi.org/10.1180/002646100549012.

21. Gora, L.; Streletzky, K.; Thompson, R.W.; Phillies, G.D.J. Study of the crystallization of zeolite NaA by quasi-elastic light-scattering spectroscopy and electron microscopy. Zeolites 1997, 18, 119-131, https://doi.org/10.1016/S0144-2449(96)00144-3.

22. Petrov, I.; Michalev, T. Synthesis of zeolite A : A review. Scientific Papers of the University of Russia 2012, $51,30-35$.

23. Bessa, R.d.A.; Costa, L.d.S.; Oliveira, C.P.; Bohn, F.; do Nascimento, R.F.; Sasaki, J.M.; Loiola, A.R. Kaolin-based magnetic zeolites A and P as water softeners. Microporous and Mesoporous Materials 2017, 245, 64-72, https://doi.org/10.1016/j.micromeso.2017.03.004.

24. Nezamzadeh-Ejhieh, A.; Tavakoli-Ghinani, S. Effect of a nano-sized natural clinoptilolite modified by the hexadecyltrimethyl ammonium surfactant on cephalexin drug delivery. Comptes Rendus Chimie 2014, 17, 49-61, https://doi.org/10.1016/j.crci.2013.07.009. 
25. Mohd Hanim, S.A.; Malek, N.A.N.N.; Ibrahim, Z.; Mad Salim, M.; Ramli, N.I.a.; Sarah, N.S.; Azam, M.A. Antibacterial Activity of Amine-Functionalized Zeolite NaY against Staphylococcus aureus ATCC6538 and Escherichia coli ATCC11229. Applied Mechanics and Materials 2015, 761, 402-406, https://doi.org/10.4028/www.scientific.net/amm.761.402.

26. Silhavy, T.J.; Kahne, D.; Walker, S. The bacterial cell envelope. Cold Spring Harbor perspectives in biology 2010, 2, https://doi.org/10.1101/cshperspect.a000414.

27. Ramirez, M.S.; Tolmasky, M.E. Aminoglycoside modifying enzymes. Drug Resistance Updates 2010, 13, 151-171, https://doi.org/10.1016/j.drup.2010.08.003.

28. Jana, S.; Deb, J.K. Molecular understanding of aminoglycoside action and resistance. Applied Microbiology and Biotechnology 2006, 70, 140-150, https://doi.org/10.1007/s00253-005-0279-0.

29. Nur Aryantie, W.; Zulhilmi Amir Awaluddin, M.; Ahmad Nizam Nik Malek, N. Characterization and Antibacterial Activity of Streptomycin Antibiotic Loaded Organo-Kaolinite. IOP Conference Series: Earth and Environmental Science 2019, 276, https://doi.org/10.1088/1755-1315/276/1/012001.

30. Wang, C.; Xu, S.; Zhang, K.; Li, M.; Li, Q.; Xiao, R.; Wang, S. Streptomycin-modified Fe3O4-Au@Ag core-satellite magnetic nanoparticles as an effective antibacterial agent. Journal of Materials Science 2017, 52, 1357-1368, https://doi.org/10.1007/s10853-016-0430-6.

31. Donovick, R.; Bayan, A.P.; Canales, P.; Pansy, F. The Influence of Certain Substances on the Activity of Streptomycin. Journal of Bacteriology 1948, 56, https://doi.org/10.1128/JB.56.1.125-137.1948.

32. Scheffers, D.-J.; Pinho, M.G. Bacterial Cell Wall Synthesis: New Insights from Localization Studies. Microbiology and Molecular Biology Reviews 2005, 69, 585-607, https://doi.org/10.1128/mmbr.69.4.585607.2005 .

33. Reddi, B.A. Why is saline so acidic (and does it really matter?). Int. J. Medical Sci. 2013, 10, https://doi.org/10.7150/ijms.5868.

34. Bardoňová, L.; Mamulová Kutláková, K.; Kotzianová, A.; Kulhánek, J.; Židek, O.; Velebný, V.; Tokarský, J. Electrospinning of Fibrous Layers Containing an Antibacterial Chlorhexidine/Kaolinite Composite. ACS Applied Bio Materials 2020, 3, 3028-3038, https://doi.org/10.1021/acsabm.0c00088.

35. Londono, S.C.; Hartnett, H.E.; Williams, L.B. Antibacterial Activity of Aluminum in Clay from the Colombian Amazon. Environmental Science \& Technology 2017, 51, 2401-2408, https://doi.org/10.1021/acs.est.6b04670.

36. Jou, S.K.; Malek, N.A.N.N. Characterization and antibacterial activity of chlorhexidine loaded silverkaolinite. Applied Clay Science 2016, 127-128, 1-9, https://doi.org/10.1016/j.clay.2016.04.001.

37. Salim, M.M.; Malek, N.A.N.N. Characterization and antibacterial activity of silver exchanged regenerated $\mathrm{NaY}$ zeolite from surfactant-modified NaY zeolite. Materials Science and Engineering: C 2016, 59, 70-77, https://doi.org/10.1016/j.msec.2015.09.099.

38. Ahmad, N.; Md Nordin, N.A.H.; Jaafar, J.; Nik Malek, N.A.N.; Ismail, A.F.; Yahya, M.N.F.; Mohd Hanim, S.A.; Abdullah, M.S. Eco-friendly method for synthesis of zeolitic imidazolate framework 8 decorated graphene oxide for antibacterial activity enhancement. Particuology 2020, 49, 24-32, https://doi.org/10.1016/j.partic.2019.04.007. 